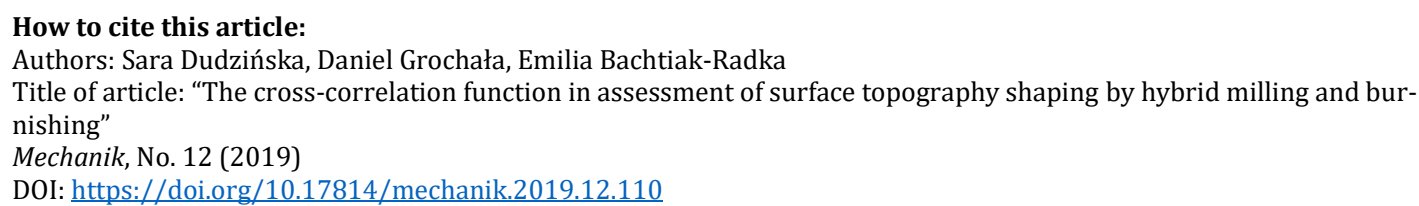

\title{
The cross-correlation function in assessment of surface topography shaping by hybrid milling and burnishing
}

\author{
SARA DUDZIŃSKA \\ DANIEL GROCHAŁA \\ EMILIA BACHTIAK-RADKA *
}

\author{
Mgr inż. Sara Dudzińska, sara.dudzinska@zut.edu.pl, https://orcid.org/0000-0002-7577-7899 - Zachodniopomorski Uniwersytet Tech- \\ nologiczny, Szczecin, Polska \\ Dr inż. Daniel Grochała, daniel.grochala@zut.edu.pl, https://orcid.org/0000-0003-2553-7739 - Zachodniopomorski Uniwersytet \\ Techno-logiczny, Szczecin, Polska \\ Mgr inż. Emilia Bachtiak-Radka, ebachtiak@zut.edu.pl, https://orcid.org/0000-0003-3366-0083 - Zachodniopomorski Uniwersytet \\ Technologiczny, Szczecin, Polska
}

In world literature much attention is devoted not only to the conscious surface shaping, but also to many problems that can be encountered during surface measurement. The development of surface metrology tries to respond to many industrial needs and keep up with sophisticated production techniques. Nevertheless the estimation and comparison of surfaces after several successive treatments is still complicated. For this purpose, the authors proposed the use of a correlation function to evaluate milled and then burnished surfaces, which is an alternative instrument to the parametric evaluation of the surface topography. This method can directly give an answer, whether the technological process has been carried out as expected. The measurements were carried out using a multi-sensor AltiSurf A520 instrument, manufactured by Altimet, according to its own developed methodology.

KEYWORDS: surface metrology, hybrid manufacturing, correlation function

\section{Introduction}

Each manufactured product must meet certain technological specification and allow for economical production. In industrial reality, this translates into shortening the production time, balancing production lines and better use of resources $[1,2]$.

For the production of very demanding and responsible parts (in the automotive, energy, medical industry, etc.), specific solutions are used to combine various manufacturing techniques within a single position (socalled hybrid production) [3,4]. Then, it is extremely important to determine the state of the surface geometrical structure (SGP) [5] and to establish quality control procedures for critical elements. The control process and creation of measurement procedures pose a serious challenge when the manufactured part must have SGP specific properties. It should also be remembered that in relation to machining with hybrid methods (which is the result of many tasks), the measurement procedures should be properly understood and extremely carefully prepared.

In recent years, many authors have dealt with the problem of creating a new quality in processes related to the surface metrology. The literature clearly emphasizes that limiting oneself to conventional methods of 2D roughness analysis and parametric 3D roughness assessment can lead to erroneous conclusions. 2D and 3D surface roughness parameters may not be sufficient to characterize a given surface feature [6-7]. Separate issues are also the need to create measurement standards and to simplify methods that can be applied in industry [8].

Considering the fact that in the world literature the scope of research on non-parametric SGP assessment is still expanding, the authors attempted a nonparametric assessment of milled and burnished surface, using cross-correlation to record the morphological changes occurring in samples. 
Cross-correlation is a measure of the similarity of two data series displaced in relation to each other. It is determined by the formula:

$$
C(\tau)=\int f^{*}(t) g(t+\tau) \mathrm{d} t
$$

where: $f^{*}$ - complex coupling of the signal $f, g(t+\tau)$ - shifted signal $g, t$ - time, $\tau$ - shift.

Given that surface measurements are two-dimensional and discrete, cross-correlation can be calculated using the following equation:

$$
\begin{aligned}
C(k, l)= & \sum_{m=0}^{M-1} \sum_{n=0}^{N-1} S_{1}(m, n) S_{2}^{*}(m-k, n-l) \\
& \left\{\begin{array}{c}
-(W-1) \leq k \leq M-1 \\
-(V-1) \leq l \leq N-1
\end{array}\right.
\end{aligned}
$$

where: $S_{1}$ and $S_{2}$ - matrices (dimensions $m \times n$ and $w \times v$, respectively), including surface measurements; $S_{2}^{*}-$ complex coupling; $k$ and $l$ - shifts in both directions.

\section{Research material}

Experimental work was carried out on samples of $42 \mathrm{CrMo} 4$ steel, tempered to hardness $35 \pm 2 \mathrm{HRC}$. The samples were milled on a DMG DMU 60 monoBLOCK machining center with a spindle axis tilted by $15^{\circ}$. Milling was performed using a torus head (WNT R1000G.42.6.M16.IK) with six cutting inserts with a diameter of $d_{\mathrm{p}}=$ $10 \mathrm{~mm}$ (RD.X1003 MOT - WTN1205). In tab. I, the machining parameters are given.

The tests were carried out for four drilling cases during milling: $f_{\mathrm{wf}}=0.7 \mathrm{~mm}, f_{\mathrm{wf}}=0.5 \mathrm{~mm}, f_{\mathrm{wf}}=0.3 \mathrm{~mm}, f_{\mathrm{wf}}$ $=0.1 \mathrm{~mm}$. Immediately after milling, selected samples were subject to burnishing using a single-ball hydrostatic tool with a bellow actuator [9], terminated with a ball of $\mathrm{ZrO}_{2}$ ceramic with a diameter of $d_{\mathrm{k}}=10 \mathrm{~mm}$. The burnishing velocity $v_{\mathrm{n}}$ was $8 \mathrm{~m} / \mathrm{min}$ and the transverse burnishing feed $f_{\mathrm{wn}}=0.12 \mathrm{~mm}$. Burnishing was carried out with a force $F_{\mathrm{n}}$ equal to $800 \mathrm{~N}$. Each of the burned fields was $11 \mathrm{~mm}$ wide.

\section{TABLE I. List of milling technological parameters adopted in the experimental research plan}

\begin{tabular}{|c|c|c|c|}
\hline $\begin{array}{c}\text { Milling speed } \\
v_{\mathrm{c}}[\mathrm{m} / \mathrm{min}]\end{array}$ & $\begin{array}{c}\text { Depth of milled layer } \\
a_{\mathrm{p}}[\mathrm{mm}]\end{array}$ & $\begin{array}{c}\text { Feed per blade } \\
f_{\mathrm{z}}[\mathrm{mm}]\end{array}$ & $\begin{array}{c}\text { Milling cross feed } \\
f_{\mathrm{wf}}[\mathrm{mm}]\end{array}$ \\
\hline & & & 0.7 \\
& 0.5 & 0.1 & 0.5 \\
& & & 0.3 \\
\hline
\end{tabular}

\section{Measurement methodology}

SGP measurements on $2 \mathrm{~mm} \times 2 \mathrm{~mm}$ fields were carried out with the use of the Altisurf A520 Altimeturf topography surface measuring machine from Altimet with a CL1 confocal sensor with a working range up to $130 \mu \mathrm{m}$ and vertical resolution of $8 \mathrm{~nm}$. The assumed scan resolution along the $X$ axis was $0.47 \mu \mathrm{m}$ and along the $Y$ axis $-5 \mu \mathrm{m}$. The collected point clouds were developed in the AltiMap PREMIUM 6.2 software. For each surface analysis, the following methodology was used:

- determination of a threshold value to remove incorrectly collected surface points,

- leveling the surface (mean plane approximated by the method of least squares),

- surface leveling (with mean plane),

- determination of selected values of topographic parameters according to ISO 25178 and cross-correlation function. 


\section{Processing the results}

Tabs. II and III present determined SGP parameters - average values of amplitude parameters and spatial parameters of reference milled samples (tab. II) and milled and then burnished samples with the force $F_{\mathrm{n}}=800$ $\mathrm{N}$ (tab. III).

TABLE II. The values of 3D surface roughness parameters of samples after milling

\begin{tabular}{|c|c|c|c|c|}
\cline { 2 - 5 } \multicolumn{1}{c|}{} & \multicolumn{4}{c|}{ Transverse feed during milling $f_{\mathrm{wf}}$} \\
\cline { 2 - 5 } \multicolumn{1}{c|}{} & $0.7 \mathrm{~mm}$ & $0.5 \mathrm{~mm}$ & $0.3 \mathrm{~mm}$ & $0.1 \mathrm{~mm}$ \\
\hline$S q[\mu \mathrm{m}]$ & 4.880 & 3.337 & 1.823 & 0.626 \\
\hline$S z[\mu \mathrm{m}]$ & 24.500 & 21.100 & 16.900 & 9.920 \\
\hline$S a[\mu \mathrm{m}]$ & 4.115 & 2.857 & 1.623 & 0.474 \\
\hline$S a l[\mathrm{~mm}]$ & 0.197 & 0.165 & 0.110 & 0.042 \\
\hline$S t r$ & 0.195 & 0.163 & 0.110 & 0.044 \\
\hline
\end{tabular}

TABLE III. The values of 3D surface roughness parameters of samples after burnishing with the force $F_{\mathbf{n}}=800 \mathrm{~N}$

\begin{tabular}{|c|c|c|c|c|}
\cline { 2 - 5 } \multicolumn{1}{c|}{} & \multicolumn{4}{c|}{ Transverse feed during milling $f_{\mathrm{wf}}$} \\
\cline { 2 - 5 } \multicolumn{1}{c|}{} & $0.7 \mathrm{~mm}$ & $0.5 \mathrm{~mm}$ & $0.3 \mathrm{~mm}$ & $0.1 \mathrm{~mm}$ \\
\hline$S q[\mu \mathrm{m}]$ & 0.628 & 0.342 & 0.304 & 0.283 \\
\hline$S z[\mu \mathrm{m}]$ & 9.757 & 7.570 & 7.543 & 6.663 \\
\hline$S a[\mu \mathrm{m}]$ & 0.537 & 0.273 & 0.234 & 0.226 \\
\hline$S a l[\mathrm{~mm}]$ & 0.282 & 0.206 & 0.159 & 0.304 \\
\hline Str & 0.291 & 0.341 & 0.237 & 0.336 \\
\hline
\end{tabular}

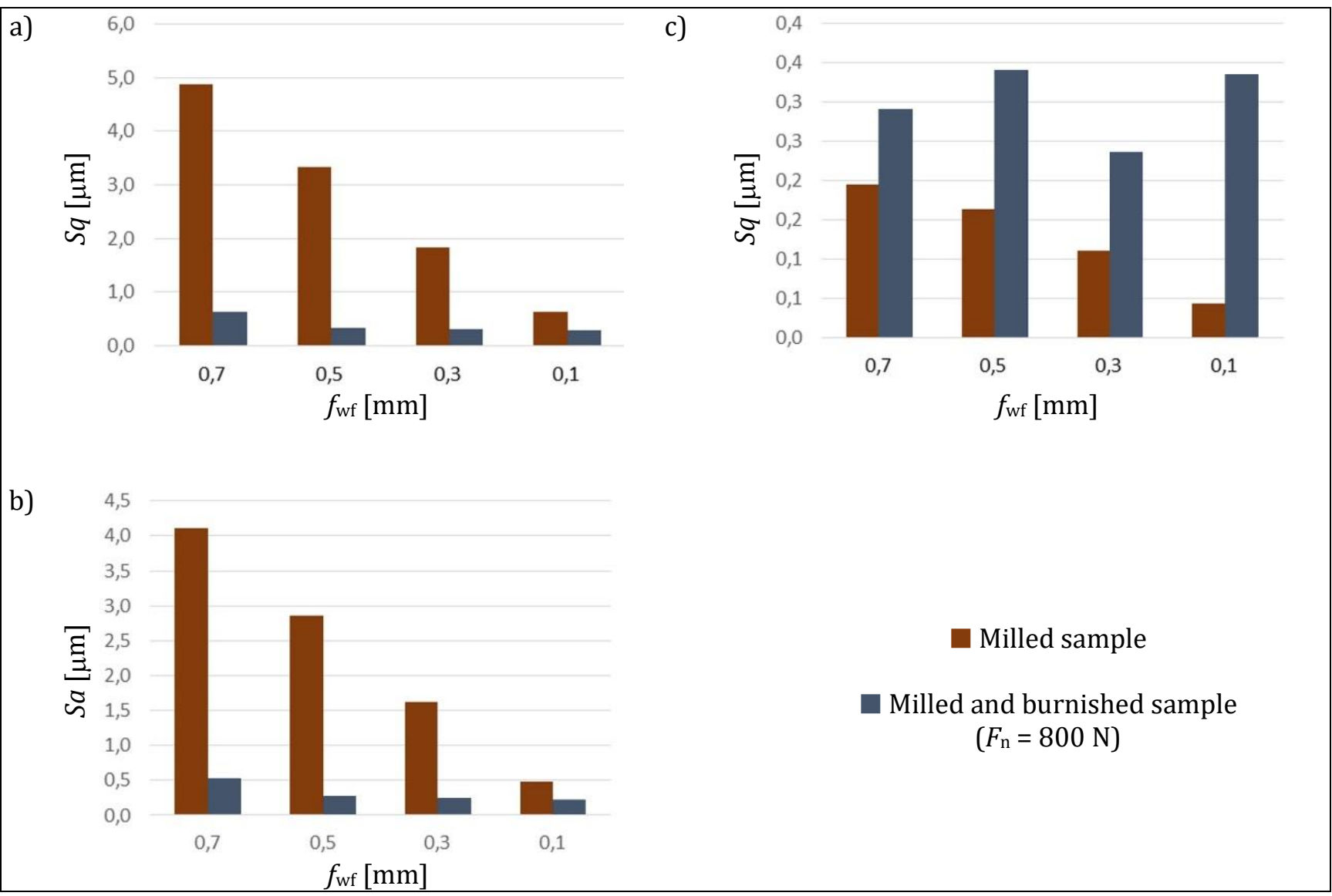

Fig. 1. $S q(\mathrm{a}), S a(\mathrm{~b})$ and $S \operatorname{tr}(\mathrm{c})$ parameter values for milled and milled and burnished samples with the force $F n=800 \mathrm{~N}$ 


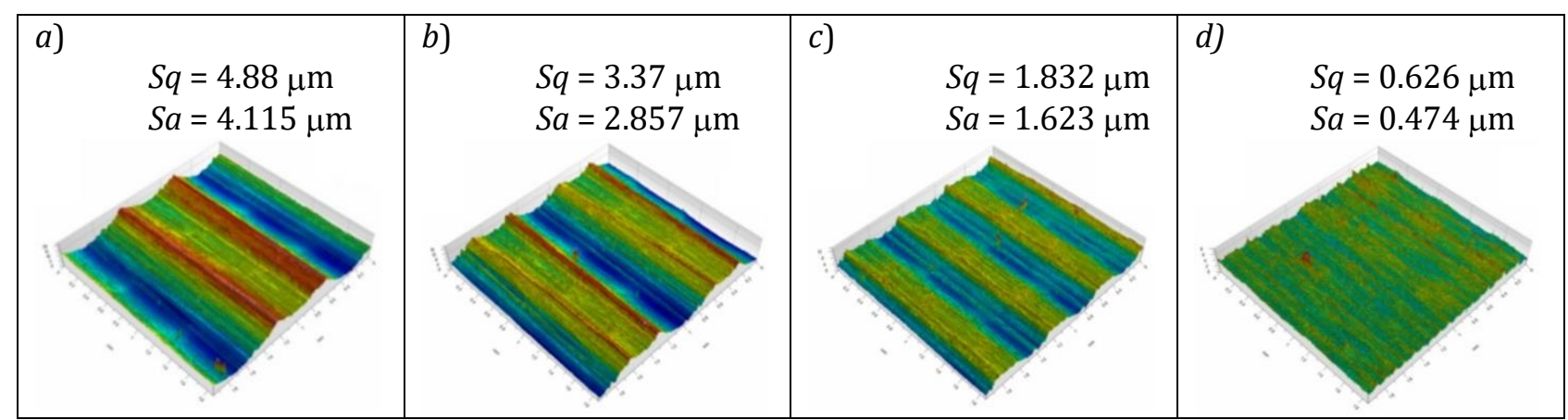

Fig. 2. Isometric images of reference milled samples with transverse feed fwf equal to: a) $0.7 \mathrm{~mm}$, b) $0.5 \mathrm{~mm}$, c) $0.3 \mathrm{~mm}$, d) $0.1 \mathrm{~mm}$

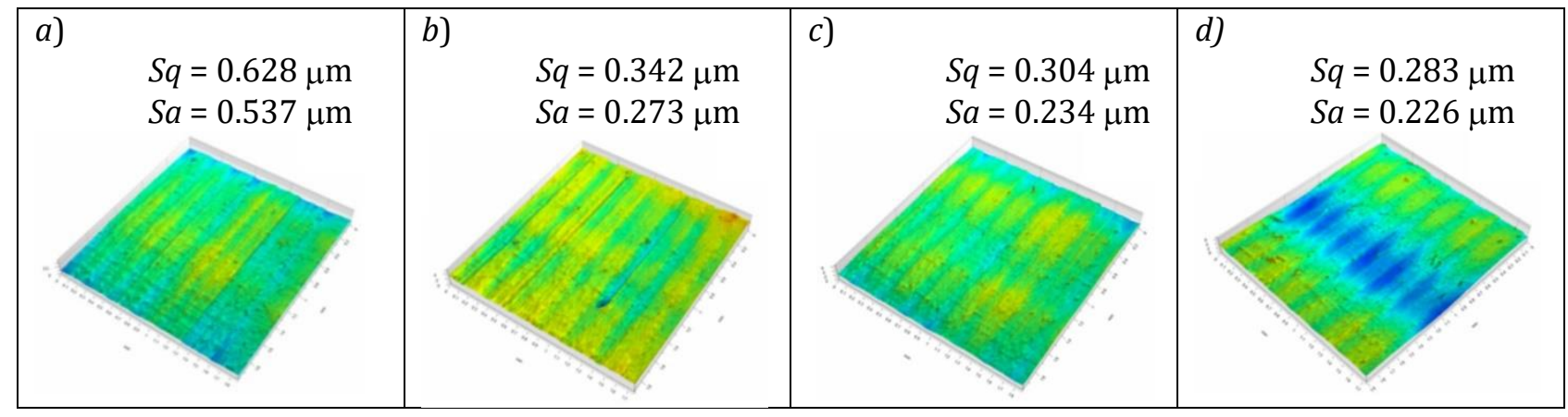

Fig. 3. Isometric images of burnished samples with a force $F n=800 \mathrm{~N}$ after milling with a transverse feed $f_{\text {wf }}$ equal to: a) $0.7 \mathrm{~mm}$, b) $0.5 \mathrm{~mm}$, c) $0.3 \mathrm{~mm}$, d) $0.1 \mathrm{~mm}$

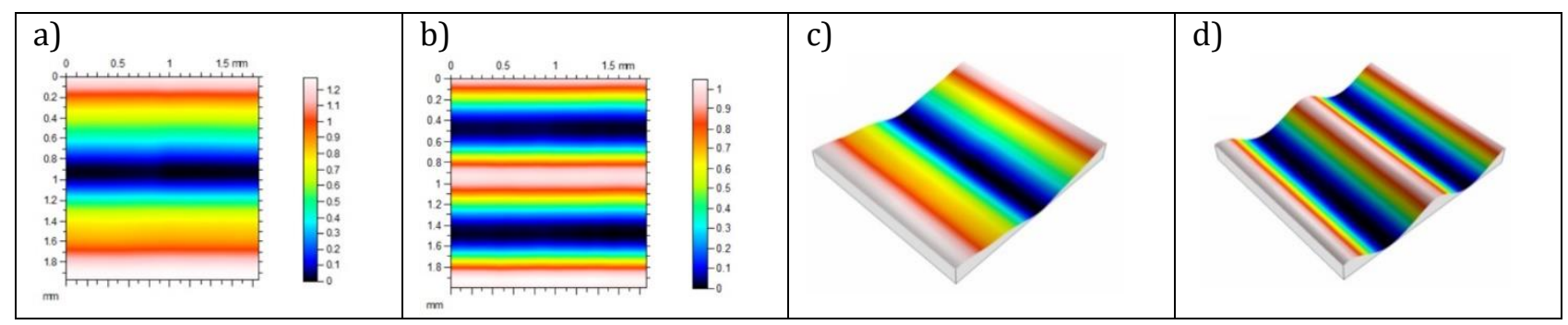

Fig. 4. Correlation results of milled surfaces as well as milled and burnished: a) and c) cross-correlation of a milled sample with feed $f_{\mathrm{wf}}=0.7 \mathrm{~mm}$ and milled with a feed $f_{\mathrm{wf}}=0.7 \mathrm{~mm}$ and burnished with a force $F_{\mathrm{n}}=800 \mathrm{~N}$; b) and d) cross-correlation of the milled sample with feed $f_{\mathrm{wf}}=0.5 \mathrm{~mm}$ and the milled sample with feed $f_{\mathrm{wf}}=0.5 \mathrm{~mm}$ and burnished with the force $F_{\mathrm{n}}=800 \mathrm{~N}$

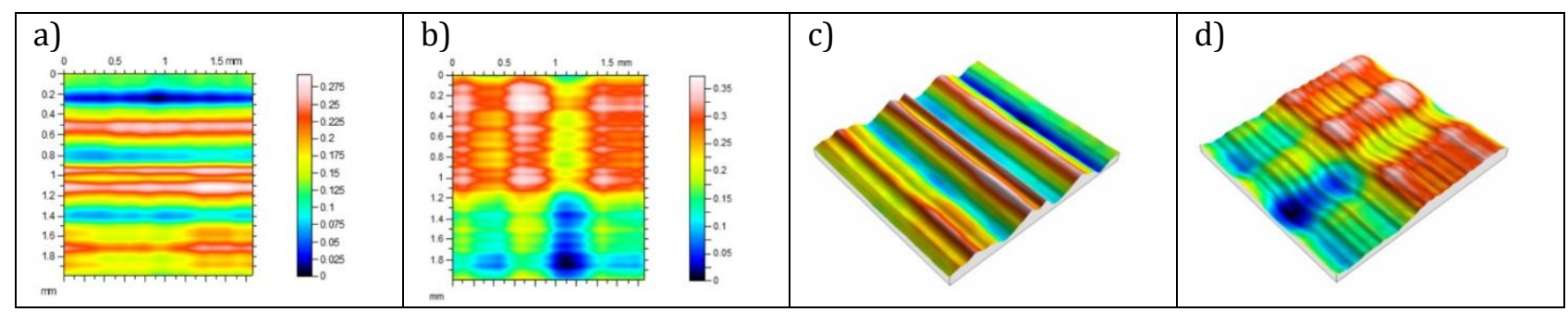

Fig. 5. Correlation results of milled surfaces as well as milled and burnished: a) and c) cross-correlation of a milled sample with feed $f_{\mathrm{wf}}=0.3 \mathrm{~mm}$ and milled with a feed $f_{\mathrm{wf}}=0.3 \mathrm{~mm}$ and burnished with a force $F_{\mathrm{n}}=800 \mathrm{~N}$; b) and d) cross-correlation of the milled sample with feed $f_{\mathrm{wf}}=0.1 \mathrm{~mm}$ and the milled sample with feed $f_{\mathrm{wf}}=0.1 \mathrm{~mm}$ and burnished with the force $F_{\mathrm{n}}=800 \mathrm{~N}$

Based on the results of the tests, it can be stated that there is a significant reduction in the amplitude values of roughness parameters $S q, S a$ and $S z$ at burnishing with $800 \mathrm{~N}$. The final effect of such process depends, among others, from the texture created at the milling stage. Fig. 1 compares the average values of parameters $S q, S a$ and Str of milled, as well as milled and burnished samples with a force of $800 \mathrm{~N}$. 
The smallest values of $S q$ and $S a$ after burnishing were recorded in the case of a sample that had previously been milled with the lowest feed $f_{\mathrm{wf}}=0.1 \mathrm{~mm}$. Comparing the $S q$ and $S a$ values of reference samples, it can be seen that the most effective was machining consisting of burnishing of samples, which in the previous procedure were milled with a transverse feed of $f_{\mathrm{wf}}=0.5 \mathrm{~mm}$. In this case, the value of $S q$ decreased by $89.8 \%$, and $S a$ - by $90.4 \%$.

Values of Sal and Str parameters significantly increased after burnishing. An increase in the Str parameter value after the second treatment indicates a uniform structure of the surface.

Figs. 2 and 3 show isometric images of recorded surfaces.

To assess the degree of removal of marks left by the milling cutter, correlation of the corresponding surfaces after milling and burnishing was performed (figs. 4 and 5). Analyzing the obtained results, it can be stated that the marks left by the milling cutter are the least visible in the case of the sample which in the pre-burnishing machining was subjected to milling with a transverse feed of $f_{\mathrm{wf}}=0.3 \mathrm{~mm}$.

\section{Summary}

Combination of parametric assessment of the surface geometrical structure and nonparametric assessment is very important in the optimization of technological processes aiming at obtaining a surface that meets stringent requirements. Cross-correlation in SGP analysis can definitely be a good helper tool to optimize hybrid technological operations. First of all, however, it allows for observing changes in the surface texture that are the result of subsequent technological operations. At the same time, it should be borne in mind that in industrial practice, such tests (even though they are very much needed) can be burdensome. Therefore, it is worth working on improving the tools that would allow creating a virtual model and thus allow obtaining a model of the machined surface. To this end, the authors undertake further research not only on the creation of mathematical models to optimize machining, but also virtual models for simulations that facilitate the understanding of changes occurring in the material during machining combining milling and burnishing.

\section{REFERENCES}

[1] Neugebauer R., Drossel W., Wertheim R., Hochmuth C., Dix M. "Resource and Energy Efficiency in Machining Using High-Performance and Hybrid Processes". Fifth Cirp Conference on High Performance Cutting. 1 (2012): 3-16.

[2] Treppe F., Hochmuth C., Junker T., Schneider R., Stoll A., "Steigerung der Ressourceneffizienz durch hybride Prozesse". Kongress Nachhaltige Produktion, Hannover 2011: 127-150.

[3] Araghi B.T., Manco G.L., Bambach M., Hirt G. "Investigation into a new hybrid forming process: Incremental sheet forming combined with stretch forming". CIRP Annals - Manufacturing Technology. 58, 1 (2009): 225-228.

[4] Zhu Z., Dhokia V.G., Nassehi A., Newman S.T. "A review of hybrid manufacturing processes - state of the art and future perspectives". International Journal of Computer Integrated Manufacturing. 26, 7 (2013): 596-615.

[5] Adamczak S. „Pomiary geometryczne powierzchni: zarysy kształtu, falistość i chropowatośc”. Warszawa: Wydawnictwo Naukowo-Techniczne, 2008.

[6] MacAulay G.D., Senin N., Giusca C.L., Leach R.K. "Study of manufacturing and measurement reproducibility on a laser textured structured surface". Measurement. 94 (2016): 942-948.

[7] Krolczyk G.M., Maruda R.W., Krolczyk J.B., Nieslony P., Wojciechowski S., Legutko S. "Parametric and nonparametric description of the surface topography in the dry and MQCL cutting conditions". Measurement. 121 (2018): 225-239.

[8] Tosello G., Haitjema H., Leach R.K., Quagliotti D., Gasparin S., Hansen H.N. "An international comparison of surface texture parameters quantification on polymer artefacts using optical instruments". CIRP Annals - Manufacturing Technology. 65, 1 (2016): 529-532.

[9] Grochała D., Sosnowski M. „Problemy technologii nagniatania powierzchni przestrzennych złożonych na centrach obróbkowych". Mechanik. 1 (2011): 14-18. 